\title{
Cuba y su imagen esperpéntica en Mi tío el empleado de Ramón Meza.
}

\section{Cuba and Its Grotesque Image in Mi tío el empleado by Ramón Meza.}

\section{Resumen}

Este artículo analiza Mi tío el empleado (1887) de Ramón Meza, novela cubana que presenta una Cuba gris en la que la Administración es absurdamente corrupta, manejada por gente avariciosa y sin educación. Muestra una clase alta preocupada sólo por su beneficio, y un país regido por los intereses de personas que no sabían nada de Cuba ni habían estado nunca en ella. Con esas y otras herramientas, Meza ofrece una imagen de la identidad española marcada por la corrupción y el deseo pecuniario, con el mensaje último de que Cuba necesitaba deshacerse del yugo colonial para poder desarrollar su propio potencial identitario y nacional. A través del estudio de la novela y su comparación con textos contemporáneos, amén de crítica postcolonial, se observa el retrato deforme y retorcido que Meza realizó del gobierno colonial de Cuba para enfatizar su propia concepción de una Cuba independiente que pudiera progresar como nación soberana.

Palabras claves

Cuba, Meza, colonialismo, independencia, imagen deforme, corrupción.

\begin{abstract}
This article analyzes Mi tío el empleado (1887) by Ramón Meza, a Cuban novel that presents a grey Cuba in which the administration is absurdly corrupt, handled by greedy and uneducated people. It shows an upper class worried only aout its own benefit, and a country ruled by the interests of people who did not know anything about Cuba or had even been. With these and other tools, Meza offers an image of Spanish identity that is defined by corruption and greed, with the ultimate message that Cuba needed to break the colonial yoke in order to develop its own national potential. Through the sudy of this novel, along with contemporary texts as well as postcolonial theory, the reader can see the grotesque portrait that Meza drew
\end{abstract}


of the Cuban colonial government to emphasize his own conception of an independent Cuba that could move forward as a sovereign nation.

Keywords Cuba, Meza, colonialism, independence, deformed immage, corruption.

En su afán por hacer fortuna y ascender en la sociedad cubana en la que vive, Vicente Cuevas, protagonista de Mi tío el empleado (1887) de Ramón Meza, se encuentra de visita en casa de D. Fulgencio para solicitar la mano de su hija Aurora y así cimentar su posición. Mientras que espera a que D. Fulgencio pueda recibirle, Vicente mira su propio reflejo en las paredes de la casa:

Arrimado al primer balaustre de la escalera admiraba el vestíbulo de la casa, hermoso, aseado, elegante y a la vez sencillo. Sus paredes, blanquedas con cal, estaban cubiertas, hasta poco más de la altura de un hombre, de blancas losas que servían de ancha cenefa, en el cual, como en un mal espejo, se veía retratado mi tío con las piernas, brazos y rostro completamente desfigurados. (108)

De esta manera, y como haría más tarde Valle-Inclán, se le ofrece al lector de forma reducida lo que el autor presenta de manera extendida en su novela: una imagen esperpéntica de la sociedad cubana del siglo XIX en la que todo es feo y deformado; una sociedad en la que la corrupción campa a sus anchas, los miembros de la administración roban a manos llenas y se aprovechan de su posición para medrar; donde la metrópolis española es dueña y señora de todo, impidiendo que Cuba pudiera crecer o desarrollarse y provocando así las llamadas a la independencia de la isla, a las cuales se sumaba el propio Ramón Meza. Esa imagen deformada, lo es de los españoles como colonizadores y de la forma de administrar la isla, ya que esto es lo que representa Vicente en el texto. 
Mi tío el empleado, considerada la novela cubana más importante del siglo XIX tras Cecilia Valdés según menciona Julio Sánchez (171), narra en primera persona las aventuras y desventuras de Manuel y su tío Vicente Cuevas en Cuba, desde que llegan como inmigrantes sin nada hasta que Vicente se convierte en conde en la segunda parte de la novela ${ }^{1}$. El texto ofrece una Cuba gris en la que la Administración ha alcanzado unos niveles de corrupción absurdos, manejada por gente avariciosa y sin educación. Muestra una clase alta preocupada sólo por su propio beneficio, y un país regido por los intereses de personas que no sabían nada de Cuba ni habían estado nunca en ella. Con esas y otras herramientas, Meza ofrece una imagen de la identidad española marcada por la corrupción y el deseo pecuniario, con el mensaje último de que Cuba necesitaba deshacerse del yugo colonial para poder desarrollar su propio potencial identitario y nacional. Este ensayo explora cómo Meza consigue ofrecer tal imagen de dos maneras. Por un lado, mediante la yuxtaposición de la novela con otros textos contemporáneos al autor que también criticaban la situación cubana y la corrupción con respecto a la dominación española; por otro lado, mediante la inclusión de crítica postcolonial para dar relevancia a un texto de tal importancia en la historia literaria y cultural de la isla, ya que como explica Ania Loomba "literary texts do not simply reflect dominant ideologies; they also militate against them, or contain elements which cannot be reconciled to them" (74). Mi tío el empleado hace precisamente eso, militar en contra de la dominación española a favor de una Cuba sin corrupción ni fraudes.

La Cuba en la que aparece la novela había pasado por dos intentos frustrados de independizarse. Primero, la Guerra de los Diez Años, de 1868 a 1878, que desembocó en la llamada Paz de Zanjón (1879). Ese pacto no satisfizo del todo a los cubanos, y provocó un nuevo intento fallido de guerra de independencia, la llamada Guerra Chica de 1879. De hecho, en 1881 la Revista de Cuba publicó un

\footnotetext{
${ }^{1}$ Es interesante que, a pesar de las alabanzas posteriores, Rogelio Rodríguez apunta que la novela permaneció "casi desconocida, hasta que en 1960 Lorenzo García Vega la exhuma" (153), y que, excepto Martí, la crítica de su tiempo la rechazó (154).
} 
documento histórico de 1869, es decir, de principios de la Guerra de los Diez Años, en el que una Comisión formada por diferentes hombres de importancia como el marqués de Campo Florido solicitaban la independencia de Cuba como mejor solución a los problemas que enfrentaba (329-37). En esa sociedad, Juan Alfonso Bravo apunta que los gastos eran enormes, y los funcionarios españoles absorbían el 75\% de los gastos fiscales (1205). En ese sentido, Inés Roldán de Montaud explica que la metrópoli impedía que en Cuba funcionaran bancos extranjeros y que se abrieran bancos cubanos (1-2), con lo cual las últimas décadas de la etapa colonial conocieron graves problemas financieros (4). Montaud va más allá y dice que la isla se arruinaba por la variedad de mecanismos que poseía la metrópoli para sacar dinero de allí, como la conversión de moneda, las transferencias por las remesas de emigrantes o los sueldos de los empleados y militares peninsulares con cargo al gobierno cubano (18).

Por su parte, Alfonso Quiroz explica que la corrupción llegó a su punto crítico en la Guerra de los Diez Años (92), y atribuye este hecho a diferentes factores. Por un lado, existían embargos indiscriminados, de los que se aprovechaban los componentes de la administración (94). Los empleados públicos y voluntarios esperaban que se les diera algo por mantener la integridad nacional, y los burócratas españoles buscaron las recompensas que creían merecer a través de la corrupción (95). Quiroz añade que muchos empleados y encargados de la recolección de impuestos se fugaron de Cuba antes de ser arrestados (96), y la Hacienda tenía tal nivel de corrupción que incluso los empleados ofrecían eliminar deudas a cambio de sobornos (98), y hasta existía el fraude aduanero: se pasaban mercancías bajo diferentes categorías a las que pertenecían para así evitar pagar los impuestos que les correspondían (99). Es interesante la afirmación de Quiroz de que se asociaba la inmoralidad administrativa a la presión colonial (106-07), uniendo así las dos quejas más extendidas de la época en Cuba y que cristalizan en una sola: si Cuba tuviera independencia y autogobierno, no se permitiría que la corrupción alcanzara esos niveles, ya que los puestos administrativos serían de los cubanos y no de peninsulares que sólo iban a América a enriquecerse y volver a 
España con el dinero que habían robado, como se verá más adelante. Esto entronca con la afirmación de Mildred de la Torre, quien explica que la corrupción políticoadministrativa ha sido vista como una de las causas de los movimientos de independencia y de la rebeldía durante el siglo XIX (9). El mismo Quiroz apunta que toda esta situación encontraba refrendo en los textos contemporáneos (94-95). Así, El país del chocolate (1887) de Francisco Moreno, que se mencionará más adelante, ya hablaba de la corrupción rampante, del hecho de que los miembros de la administración robaban a manos llenas, y también de los fenómenos ya mencionados por Quiroz sobre el tráfico de influencias, los sobornos, y el fraude en las aduanas para evitar pagar aranceles. También Cuba por dentro (1871) de Jacinto Hernández criticaba la corrupción administrativa y la incapacidad de la burocracia, al igual que hacía Cuba y sus jueces (1887) de Raimundo Cabrera.

En ese contexto, aparece Mi tío el empleado, y lo primero que ofrece es la llegada a la isla de Cuba de un barco procedente de España que lleva a La Habana a los dos protagonistas: Miguel, el narrador de la historia, y su tío Vicente Cuevas, auténtico protagonista de la novela y alrededor del cual se centra toda la acerada crítica de Meza. Jon Ander Ramos explica que la población española emigraba a Cuba porque la situación económica no era buena en la península (1044), e incluso el gobierno español favorecía la emigración a Cuba y Puerto Rico poniendo obstáculos a la emigración a otros países americanos (1045). Ya desde el principio, el texto se encarga de mostrar una aguda diferencia entre España y Cuba en la percepción que los dos inmigrantes tienen de la isla:

[...] todo esto se presentaba a la contemplación de dos viajeros [...] con cierto maravilloso atractivo de que no les era posible sustraerse. Y no se debe de extrañar que tan honda impresión les causara: no habían visto sino vetustas casas de muy pobre arquitectura, y nunca, más allá de las diez o doce reunidas que constituían el villorrio. (13) 
Con este párrafo se crea un contraste en el que Cuba aparece como un país superior, más hermoso, más digno y rico, con lo cual el autor sienta las bases para el resto de la crítica que se va a llevar a cabo a lo largo del texto. Los mismos españoles se extrañan de las maravillas que ven en Cuba, y si los propios ciudadanos provenientes de la metrópoli de la que se quería la independencia se maravillan, la conclusión es que la isla se posiciona en un nivel superior al de España, y por tanto merecedor de su independencia de ella. Para reafirmar esta yuxtaposición, el narrador ofrece la siguiente imagen del almacén del puerto:

Anduvimos bajo el largo cobertizo de zinc del muelle donde había una profusión de sacos, barriles, cajas de todos tamaños, enormes ruedas dentadas de hierro, grandes pailas y masas de metal, almireces, tubos de barro, tinajones, flejes, rieles, duelas, cántaras, jarras, todo en grupos, o bien separados, o ya en hileras, o en montones más altos que un hombre; pero sin confusión, sin desorden, pues de trecho en trecho había hombres que a manera de pastor de ovejas no dejaban que se les descarriara un solo objeto. (18)

Por un lado, es necesario mencionar que la aduana era uno de los lugares donde más se daba la corrupción. Francisco Moreno explica que en las duanas cubanas se llegaban a robar hasta 4 millones de pesos, siendo este dinero que el gobierno dejaba de recaudar para otros fines (32-33). Además, la cantidad de objetos mencionados por Meza entronca con las palabras de Moreno, quien explica que el tráfico en las aduanas es tanto, que es difícil saber lo que hay o lo que va entrando (131-32). Por su parte, Raimundo Cabrera, otro autor contemporáneo de Meza, también critica duramente esta situación al explicar que al entrar a Cuba se puede evitar la inspección de maletas e incluso de cargamentos comerciales pagándole al empleado de la aduana, quien solía ser de origen español (13). Por eso, Ania Loomba apunta que en las colonias existía gran movimiento tanto de bienes como de personas, pero ese movimiento estaba muy inclinado hacia el lado 
europeo, produciendo la riqueza de los colonizadores en detrimento de los colonizados (4). Con esto en mente, el fragmeto citado cobra un nueva dimensión en la que ese discurso de abundancia y orden en la aduana tiene una finalidad contraria al desarrollo de Cuba.

Por otro lado, el fragmento citado da la sensación de orden y de buen funcionamiento, la cual contrasta con la de corrupción, dejadez y abandono de la administración que se irá desarrollando a lo largo de la novela para producir el mensaje último de que la metrópoli no era capaz de producir el orden necesario para gobernar Cuba, y por lo tanto un cambio se antojaba necesario para el futuro bienestar cubano. Este tipo de contraste aparece en otros momentos, por ejemplo, durante su primera noche en Cuba los dos protagonistas salen a pasear con Domingo, un paisano que les hace de cicerone, y se maravillan con las tiendas:

Las vidrieras de los establecimientos repletas de mil objetos de fantasía, de géneros, de cristales; los mismos establecimientos en donde largas filas de luces producían vivísima claridad que se reflejaba en los suelos de blanco y pulido mármol y en los filos dorados de los armatostes y mostradores, eran admirados detenidamente por nosotros. (27)

El choque que se produce entre lo que ellos están acostumbrados a ver y lo que se encuentran en Cuba posibilita que se repita la sensación de superioridad de una Cuba instalada en la mente del narrador en una esfera superior. El colocar a Cuba en esa posición ayuda al autor a enfatizar el mensaje de que un lugar así no debe estar bajo el yugo colonial sino que necesita la autodeterminación. Y para subrayar dichas diferencias, al ver todas esas maravillas, Vicente pregunta: “¿Dime, Domingo [...] y esto no se lo roban?” (28). Esta pregunta es sintomática de, y crítica con, una mentalidad española que no entiende el ver algo de valor sin querer llevárselo. Y, al mismo tiempo, entronca con el aspecto colonialista que pensadores como Meza combatían, y que refleja a las claras la idea de que la metrópoli robaba lo que existía en América, manteniendo así a estas naciones en 
estado de subalternidad sin importarle su futuro o bienestar. La importancia de toda esta escena viene ejemplificada en las palabras de Anibal Quijano, quien crea una diferencia entre dominadores que toman lo que les sirve y los dominados que han de adoptar la cultura que se les impone (209-10). Esa diferencia ya era observada por Raimundo Cabrera en su texto de 1887. Cabrera distingue entre "los advenedizos de la Metrópoli," unidos por el interés "de la explotación" y que se imponen "con fuerza abrumadora," y la gente de Cuba, "que paga y sufre y soporta la injusticia de los explotadores" (26-27). Esa situación crearía una dicotomía entre una cultura superior a otra, y que por tanto se sentiría legitimada para robar y aprovecharse, como se observa en la novela de Meza. Sin embargo, los fragmentos citados anteriormente proponen una Cuba que en realidad es superior, con orden y riqueza, y una España inferior, de ladrones y aprovechados. De esa forma, la legimitidad estaría del lado cubano para reclamar la independencia de la que el mismo Meza era partidario, como menciona Manuel González Freixas (40). Este fragmento, además, cobra importancia en relación con las palabras de Ania Loomba siguiendo a Abdul JanMohamed: el aspecto discursivo y el material de la colonización no tienen por qué estar separados, típicamente para autorizar la misma colonia (99). Sin embargo, en el fragmento citado se muestra cómo el discurso maravillado de los colonizadores legitima justamente lo contrario, es decir, el hecho de que la isla está por encima de España, y por tanto no merece la subalternidad. Además, es interesante traer a colación las palabras de Homi Bhabha al hablar del poder colonial: "The exercise of colonialist authority, however, requires the production of differentiations, individuations, identity effects through which discriminatory practices can map out subject populations that are tarred with the visible and transparent mark of power" (153). A la luz de estas palabras, los fragmentos citados funcionarían de manera contraria a la expresada por Bhabha. No crean una diferencia para mostrar la superioridad del poder colonial y de la metrópoli, sino que funcionan como recordatorio de la superioridad cubana sobre la metrópoli española, a pesar del complejo de superiridad que ésta se empeñe en mantener. En conexión con estas ideas, Elleke Boehmer explica que "in the written 
word [...] early nationalists found a compelling medium to counter colonialism's self-representations, to write a self-defining story" (15). De esta manera, las descripciones de Meza sirven para crear una imagen propia, en oposición a las ideas que tienen los europeos, y que ofrece una Cuba maravillosa en sí misma, sin deformaciones ni esperpentos, pero maltratada por los dominadores europeos, estos sí, esperpénticos y deformes en sus ideas y comportamientos.

El complejo de superioridad mencionado se revela en Vicente, el protagonista, en forma de una carta de recomendación que él mismo blande como algo de mucha importancia en cuanto algo no le agrada, como la posada donde van a alojarse: "yo vengo recomendado por el marqués de Casa-Vetusta, el hombre más rico y más grande de Madrid [...], y yo no soy un tonto, veo que esta casa no me corresponde" (23). Primero, se puede observar la conexión entre este hecho y las ideas de Loomba: el enlace entre la representación textual y la colonialidad. Así, la carta funciona como la representación textual de una superioridad colonial que sólo existe en la mente de Vicente. Cree que la carta de recomendación y sus relaciones en España le otorgan un nivel superior, aunque sea un pobre desgraciado, ignorante y casi analfabeto, como se comprobará más adelante, y de nuevo en el contraste en donde Meza hace aparecer la crítica; Vicente es un cero a la izquierda con delirios de grandeza y una carta de recomendación que da pábulo a esos delirios. De esa manera, se muestra lo que significaba Cuba para la metrópoli: un lugar donde medrar, donde enriquecerse aunque los méritos propios no lo justificaran, provocando así la merma de la misma isla y el menoscabo de las posibilidades de los cubanos. Es entonces esclarecedor que Silvia Bermúdez, al citar a Emilio Ferreiro hablando sobre el emigrado gallego Curros Enríquez, diga que a Enríquez le dolía que España considerase a Cuba una provincia española o un protectorado menor (336), mostrando así esa pretendida superioridad colonial que Meza se encarga de menoscabar. Por otro lado, el mismo nombre Casa-Vetusta refleja una crítica a una sociedad caduca, casi feudal, y por extensión a un sistema colonial que 
la sociedad cubana consideraba anticuado y que mantenía a Cuba bajo su yugo ${ }^{2}$. Con todo esto, entonces, no extraña que los intelectuales clamaran por una independencia que consideraban necesaria para el futuro de Cuba.

La importancia de la carta de recomendación viene porque Vicente no va a América de vacaciones, sino que tiene ambiciones de fama y fortuna. La carta es específicamente para D. Genaro, un alto funcionario de la isla que no brilla por su esfuerzo, ya que llega a la oficina "como a la una" (32). La carta le pide que les dé empleo a los dos visitantes, y aunque D. Genaro no está muy convencido al principio, acaba por hacerlo, pensando que precisamente porque ninguno tiene mucha idea, va a poder aprovecharse de ellos para enriquecerse. Este fenómeno de padrinazgo era una institución que aparece en otros textos de la época, como el de Francisco Moreno, en el que se dice que "[...] los que dan credenciales con objeto de participar del fruto de las rapiñas de sus ahijados, sin exponer la honra ni el pellejo [...] ni merecen otra cosa que un presidio" (13-14). Se puede ver, entonces, que existían en demasía los casos de trabajadores enviados desde España con recomendaciones para el beneficio de los que las daban.

Así, D. Genaro los pone a trabajar, y ya desde el principio es posible observar que efectivamente, ni Manuel ni Vicente saben mucho de nada, y el aparato burocrático en el que trabajan aparece siempre muy criticado. Lo primero que hacen es llevarlos a un despacho "cuyas paredes no se veían pues estaban cubiertas por pilas de expedientes tan altas que tocaban el techo" (41). Esta imagen ofrece la idea de una burocracia que no funcionaba, ya que se acumula tanto el trabajo, lo cual queda refrendado por las tareas encomendadas a Manuel y Vicente: “sacudir aquella papelería y volver a poner otra vez en su lugar con mucho tiento y

${ }^{2}$ Esta conexión se explicita también en los nombres de los barcos que hay en el puerto: "La derrota de los cien mil gabachos," "El vencedor de ambos mundos," "Velero del puerto de Madrid," "Don Pelayo en las Sierras de Covadonga,” “iAbajo los carlistas!," “AArriba Isabel II!,” y el de la posada donde se alojan: "El león nacional." Con estos nombres, Meza agudiza su burla de una nación española anclada en la historia y en los sistemas coloniales e imperiales. Elleke Boehmer explica que los movimientos nacionalistas han dependido de símbolos y personajes del pasado para reafirmar su dignidad (5-6). En el caso de Meza, una vez más, los usa de manera contraria. Estos nombres y símbolos de la historia colonial e imperial española funcionan como recordatorios negativos de esa historia de imposiciones y de lo absurdo que resulta en la época en que escribe. 
cuidado, cuanto legajo tocáramos" (41). Es decir, el trabajo es sólo cosmético, en realidad no soluciona nada, ya que el papeleo vuelve a su sitio sin que se haya avanzado con él, poniendo así de manifiesto la inutilidad y circularidad de la burocracia isleña (es decir, española), que sólo daba trabajo a los nacidos en la Península, y además no solucionaba ninguno de los problemas relacionados con las instancias que sólo desempolvan. Esta idea tiene un reflejo en otros textos contemporáneos de Meza. Así, el texto de Jacinto Hernández mencionado con anterioridad apunta que "libros disformes harían suponer que en ellos se trabaja mucho, pero sus hojas están [...] blancas" (9). En ambas instancias se critica que la burocracia no ayudaba a nadie más que a los propios empleados, que se enriquecían mientras no hacían nada.

En ese trabajo mencionado, el hecho de que Manuel y Vicente son marionetas para que D. Genaro consiga enriquecerse queda demostrado con el episodio de D. Benigno, descrito como un empleado laborioso, honrado y conocedor del oficio $(47-48)^{3}$. A pesar de todo eso, D. Genaro consigue que lo despidan, ya que D. Benigno tiene papeles "en los cuales ya había puesto codiciosas miradas don Genaro" (49), para que Manuel y Vicente trabajen allí. De nuevo Francisco Moreno recoge esta situación en su crítica de la corrupción en Cuba, al explicar que "al empleado digno y probo que sabe cumplir y cumple con los deberes que su cargo le impone, se le tienden lazos [...] para arrojarle fuera del destino que desempeña, para que se dé entrada a otro que favorezca los intereses particulares con perjuicio de los del Tesoro" (69). Esto es exactamente lo que ocurre con D. Benigno, se le despide para sustituirlo por Vicente, el cual es un inepto en su trabajo pero sirve a los intereses pecuniarios de D. Genaro y el marqués de Casa-Vetusta.

Sin embargo, desde bien pronto se hace patente que Vicente no sabe lo que hace, apenas sabe escribir y no tiene conocimiento de lo que debe hacer en su posición (65-66). El colmo de lo absurdo llega cuando le dice a Manuel que debe

\footnotetext{
${ }^{3}$ El personaje de D. Genaro no existe sólo en la novela de Meza, sino que representa un tipo que se podía encontrar en la vida real. Así, Francisco Moreno explica la vida de un tal Anibal Arriete, quien ascendió en la administración a través de la corrupción, la extorsión y el robo (178-84).
} 
escribir un informe, pero no sabe decirle qué tiene que escribir, y cuando lee lo que Manuel ha hecho, sólo sabe decir que está mal, con el resultado de que deben pedir ayuda a otro burócrata, sólo para que éste les diga que lo que había hecho Manuel en un principio era correcto (67-68). Así, se critica no sólo la incapacidad de los burócratas puestos a dedo por nepotismo en la figura de Vicente, sino también, y como consecuencia de lo anterior, la inutilidad de una burocracia que debe doblar esfuerzos para realizar una sola tarea. Francisco Moreno se hacía eco de la misma idea al exclamar “¡Va a Cuba cada ineptitud que da vergüenza!” (15). Mildred de la Torre añade que este tipo de situación tuvo transcendencia en grupos urbanos, donde había quejas por el nombramiento a cargos políticos de personas emparentadas con cargos públicos o eclesiásticos, y que a veces ni siquiera cumplían con los requisitos del puesto (12); la relación con Vicente Cuevas no podía ser más acertada. Por su lado Aníbal Quijano critica que desde el principio del fenómeno colonial se fue creando una relación entre capitalismo y raza que desembocó en una distribución racista del trabajo: los europeos podían hacer cosas que los negros, mestizos o indios no podían, sobre todo trabajo asalariado (203207). En el texto de Meza, ese fenómeno se muestra en la obtención de empleos por parte de gente tan incompetente como Vicente Cuevas, y su consiguiente complicidad con D. Genaro en el robo y fraude, lo cual sólo lleva a la dilapidación de recursos cubanos en beneficio de los europeos. En conexión con estas ideas, el mismo Ramón Meza, que fue presidente del Comité de Protección al Inmigrante, escribió en 1906 en defensa de la imigración bajo la condición de que ésta resultara útil al país, pero criticaba duramente a los inmigrantes holgazanes y parásitos que perjudicaban a la sociedad en general (1906, 329).

Esta crítica continúa con los planes que realizan para enviar un informe a España. Para empezar, D. Genaro les insta a que escriban "con todo estilo galano, florido y castizo; esto da mucho realce a los informes" (71), es decir, lo importante es que la lengua suene bien, aunque el contenido sea vano o estúpido. En conexión con este hecho, Elleke Boehmer, al hablar del uso de la literatura como elemento central al proceso de colonización y al de independencia, explica que incluso los 
textos formales como informes legales estaban llenos de lenguaje ornado y figurado (5). En el caso de la novela de Meza, al poner en los textos legales de los colonizadores un lenguaje florido pero sin contenido, se consigue reafirmar la idea de una colonialidad abusadora a la que no le interesa más que su propio interés y por tanto es nociva para Cuba. La misma Boehmer explica que el Imperio también se entiende como texto, no sólo en términos de reyes y ejércitos, sino también de informes de funcionarios (14). En ese sentido, los informes de D. Genaro y Vicente cobran importancia en cuanto representan al Imperio, a la colonia, pero aparecen ridiculizados, deformados: son textos ampulosos con un contenido tan trivial como solicitar sillas y escaleras, que al final son para favorecer su afán de lucro. Así, de nuevo la metrópoli queda criticada en favor de la colonia.

Además, se habla de que el informe debe realizar un "viaje a través del Atlántico por cuenta del estado, iy luego que siguiera empaquetado viajando en ferrocarril hasta Madrid!” (71), con lo cual se cuestiona la eficacia de un sistema burocrático en el que la información tardaba tanto tiempo en alcanzar su destino que ralentizaba el buen funcionamiento del mismo sistema. El colofón a todo esto viene del hecho de que ese informe que tiene que atravesar tantas etapas, no es más que una solicitud para construir una escalerilla que una el despacho de D. Genaro con el espacio donde trabajan Manuel y Vicente y que contiene los documentos que desea el primero. Es decir, se ridiculiza un proceso tan extenso para lograr algo tan mínimo como construir una escalerilla, que por otro lado le servirá a D. Genaro para entrar a sus anchas en la sala de los documentos y usar los que necesite para hacer fortuna ${ }^{4}$. Todo esto ofrece una imagen deforme, esperpéntica, de la burocracia española: era un sistema absurdo, lento, ineficaz, laberíntico y útil sólo para los que sabían aprovecharse de él para hacerse ricos, los cuales eran siempre

\footnotetext{
${ }^{4}$ En el texto se habla en diferentes ocasiones de las instancias que deben enviar a España para que les den sillas y bancos (104-105). Esto hace que la crítica se haga más efectiva, ya que plantea la pregunta de qué clase de burocracia exige semejantes requisitos para algo tan nimio, cuando los recursos deberían usarse con más eficacia y en beneficio de Cuba.
} 
los españoles enviados por la corona a trabajar allí ${ }^{5}$ Francisco Moreno también apuntaba que la burocracia era la peor lacra de Cuba al hablar de las desdichas de la isla: "ninguna tan grave y tan trascendental, como esa combinación de ignorancia, insolencia, inmoralidad y favoristismo, que se llama burocracia" (18889); todo lo cual queda ampliamente demostrado en la novela de Meza y en las figuras de Vicente Cuevas y D. Genaro.

Esas situaciones mencionadas dan cuenta de una situación de corrupción en la que la gente de la Península se aprovechaba y se enriquecía a costa de los recursos de la isla, lo cual queda claro cuando D. Genaro le dice a Vicente que "tengo en Madrid personas cuya influencia jamás ha defraudado mis esperanzas" (77), y se reafirma cuando, al recibo de un informe de Madrid, el mismo D. Genaro explica que "en los correos sucesivos irán llegando los informes con la concesión de cuanto en ellos se pide" (79), subrayando así que desde la Península se fomentaba esa corrupción, ya que de esa manera se enriquecían tanto los que estaban en Cuba, como los que estaban en Madrid. Y efectivamente, ya que a la afirmación de Vicente de que "¡no hay más que tener buenas influencias en Madrid!" (98) cuando empiezan a recibir todas sus solicitudes aprobadas en corto espacio de tiempo, Manuel explica que "junto con nuestros informes recibíamos otros del antecesor de don Benigno, y eso que [...] hacía treinta años que éste comenzó a desempeñar su empleo" (99). Aquí se une la crítica a la lentitud de la burocracia con la crítica a la corrupción transoceánica. Es decir, la burocracia, lenta normalmente, empieza a funcionar eficazmente cuando sirve a los deseos de fortuna de las personas que la rigen a ambos lados del Atlántico, pero no por necesidad de Cuba.

${ }^{5}$ Esta crítica a lo laberíntica e ineficaz que es la burocracia aparece en el siguiente diálogo entre Vicente y Manuel:

- ¿Te ríes?, ¿pues cuánto aventuramos a que si vamos los dos solos por esas oficinas de Dios nos perdemos, sobrino, nos perdemos sin remedio? ¿No has visto el mapa que tiene colgado D. Genaro en su despacho? [...] Pues sí, hombre, en ese mapa están dibujadas todas las oficinas, sus nombres, y el camino que hay para llegar a ellas.

Así, de manera tan gráfica, Meza se burla de una burocracia tan absurda y esperpéntica que incluso para encontrar las oficinas hay que usar un mapa. 
Estas ideas sobre la ineficacia de los burócratas y la corrupción de los funcionarios aparecen como una sola cuando se explica lo siguiente sobre las cuentas de gastos: “-Dos y dos son cinco y cinco doce... De sumar cuentas de gastos por este nuevo sistema era de lo único que tenía que ocuparse mi tío. Y don Genaro sin más averiguaciones cargaba con todo el resultado" (82), es decir, se inflaban las cuentas de gastos para que ellos pudieran quedarse con el sobrante una vez terminada la obra, de ahí que todo se apruebe con tanta celeridad desde la Península: ese sobrante también revierte en las cuentas de los que les apoyan en España, como el conde de Casa-Vetusta, cerrando así el círculo de la corrupción. De algo similar se hace eco Jacinto Hernández al explicar que los gobernantes de Cuba inflaban los números de los insurrectos cubanos para que el gobierno peninsular enviara más soldados que favorecieran "el enriquecimiento del que los pide y el de sus cómplices" (35).

El problema de la conexión con la Península era que los acontecimientos políticos en España también afectaban a Cuba. Así, cuando llegan un día a la oficina y se encuentran una gran alboroto, les explican que “¡Nos echan [...]! Ha caído el ministerio" (120). Con el cambio en la escena política española, viene el cambio en América, ya que la nueva administración quiere alejarse de lo que ha hecho la anterior. Esta idea se ve reforzada por la destrucción de la escalerilla que habían construído ya que "este ministerio desaprueba todo lo que hizo el anterior" (121). Esto redunda en la crítica a una política colonial caótica y sin rumbo, en la que no existe un plan específico y cada gobierno se dedica a hacer lo que le parece, y sobre todo a deshacer lo del anterior, sin considerar los intereses de Cuba misma. Bajo estas circunstancias, entonces, no extraña que se levantaran voces críticas con esa adiministración y que disentían del dominio español sobre la isla. Así, tanto deshace un gobierno lo que ha hecho el anterior, que los funcionarios van a la cárcel. Pero incluso en esta tesitura, Meza no deja de mostrar la corrupción de los funcionarios españoles. De esa manera, D. Genaro, quizá el ejemplo de mayor corrupción de la novela, es el único que se libra de la prisión, y consigue que los demás puedan escaparse a México pagando a los guardias (131-142). 
Al regreso de Vicente de México seis años después, da comienzo la segunda parte de la novela, en la que se ha operado un cambio en el protagonista para transformarse en el conde Coveo. Ya su primera descripción muestra a una persona diferente: "un hombre gordo, hermosote, bien afeitado, vestido con toda corrección y elegancia de paño negro" (145). Esta descripción ya da cuenta de una nueva posición social. Vicente Cuevas (ahora el conde Coveo) ha ascendido en la sociedad, ya no es el funcionario pobre e ignorante, sino que se ha adaptado a la vida en América y ha hecho lo que todos los inmigrantes deseaban: enriquecerse. El mismo bastón que empuña es también sintomático: "un bastón de caña de Indias, cuyo puño era una gran corona condal" (145). Esta mezcla de elementos explica de manera alegórica la situación cubana: un cuerpo de material americano rematado por un elemento español y aristócrata que simboliza la autoridad, el colonialismo y el control sobre una isla que reclamaba su independencia.

El conde va tan bien arreglado porque se dirige al teatro a un banquete en su honor, en el que la descripción pantagruélica de toda la comida que allí se sirve no hace más que añadirse a la crítica de ese grupo social que se ha enriquecido haciendo negocios turbios en América, como el mismo conde. Y esa crítica aparece enfatizada cuando, tras salir todos del teatro, los criados los imitan, se ríen de ellos e incluso hacen burla del discurso vacío y sin sentido del conde (157). Con esta imagen, reflejo esperpéntico de la alta sociedad, se consigue crear esa crítica acerba al grupo de gente que controlaba la isla social, política y económicamente. Como apunta Manuel González Freixas la abundancia de comida y los banquetes son también señal de la sociedad corrupta y de derroche que denuncia Meza (47). Para rematar la escena, un mendigo entra en la sala y se mete debajo de la mesa a recoger las migajas que puede (157). Con ese contraste, la imagen queda completada: son los ricos españoles los que tienen lo mejor, los que controlan todo y se han enriquecido de cualquier manera, y los pobres han de recoger sus migajas para poder sobrevivir, máxime cuando el mendigo resulta ser D. Benigno, el empleado al que D. Genaro consiguió despedir al principio de la novela, como más adelante se comprobará. José Martí se hizo eco de esto mismo en su crítica a la novela al 
explicar que mientras los empleados engordan, el resto del país "pasa en la sombra discreta de la novela como una procesión de fantasmas lívidos y deshuesados" (s.p.).

La apariencia de Vicente ha cambiado, pero el fondo sigue siendo el mismo. Aunque ahora sea un conde, no deja de ser un personaje que sólo quiere aprovecharse de su situación, enriquecerse a costa de quien sea, y haciendo negocios con quien sea, fiel representante de la colonialidad tóxica que acuciaba a Cuba. Así se muestra cuando tiene una reunión en su despacho con otros personajes de alta alcurnia, como un marqués (185). Pronto queda bien claro que el conde y el marqués tienen negocios turbios de los que sacan mucho dinero, sobre todo cuando, al preguntársele por los contactos en España, el conde responde que "lo de allá es lo de menos [...]; figúrense ustedes que allá está don Genaro de los Dées, primo mío, persona de influencia suma en Madrid y además allá está también el marqués de Casa-Vetusta, cuya voluntad es acatada por todos" (185-86). Con esta conexión transatlántica entre individuos que ya han quedado establecidos como ladrones y timadores, se manifiesta la crítica a un sistema colonial en el que los cubanos sacaban poco de provecho, y eran los españoles los que salían ganando: movían los hilos desde la Península y se llevaban la mayor tajada. Dicha conexión corrupta queda bien aclarada cuando el mismo conde dice que

[...] los muy bribones de don Genaro y el marqués de Casa-Vetusta se están allá, en Madrid, muy tranquilos gozándose su dinero, codeándose con los hombres más importantes de la gobernación en banquetes y reuniones, dándose mucho tono, tomando cómodamente su parte de ganancia, y mientras tanto yo me estoy aquí comprometiéndome y trabajando como un burro para enriquecerlos a ellos y darles recursos y prestigio ... (242).

Este fragmento refleja muy a las claras la crítica de la novela a la situación de Cuba en su relación con España: la metrópoli enviaba gente a trabajar en puestos que sólo estaban reservados para ellos, y la gente que trabajaba en la administración 
isleña se aprovechaba, era corrupta, y únicamente se preocupaba de sacar dinero para ellos mismos y sus padrinos en la Península, que eran los que los habían colocado allí en primer lugar. En esas circunstancias, no es de extrañar que los intelectuales cubanos como Meza denunciaran esta situación y reclamaran la independencia de Cuba. En conexión con esta situación, resulta interesantísimo el caso del Capitán General Manuel de Salamanca, mencionado por Alfonso Quiroz. Este autor explica que dicho militar escribió en 1890 una carta al ministro de Ultramar en la que explicitaba sus intenciones de limpiar la corrupción de la isla para poder gobernarla mejor. En dicha carta, "señalaba como principales opositores de sus esfuerzos [...] a los "caciques" integristas conde de Casa Moré y Manuel Calvo, sus agentes en Madrid y los mismos funcionarios implicados en los casos de corrupción descubiertos." (104). De esta manera, se observa que las críticas de la novela tenían su raíz en casos auténticos ocurridos en Cuba y que la realidad y la ficción no estaban muy separadas en esta ocasión.

Ese concepto sobre los funcionarios que se aprovechaban de su puesto queda reflejado en lo que hace el conde en su despacho en el capítulo irónicamente titulado "Se trabaja activamente en las oficinas" (241). El capítulo empieza con una conversación entre el conde y su mano derecha D. Mateo, quien antiguamente era su maestro en la escuela en España, en la que se discute el dinero que han ido sacando de diferentes personas en sus diversos timos (241), pero lo más sintomático son los pensamientos del conde: “¡Venir [...] a aquella oficina cuyos asuntos maldito lo que le importaban si no producían mucho y pronto!" (241). La crítica de Meza, por tanto, queda enfatizada con la presencia de personajes como el conde, quienes sólo piensan en enriquecerse, no les importa el puesto que tienen y que podía desempeñar alguien de Cuba, y únicamente están allí para poder aprovecharse y volver a España millonarios.

Con ese objetivo en mente y para añadir más a su riqueza, el conde Coveo anda en busca de una esposa, alguien con quien compartir todo lo que tiene, según él mismo (174), pero no sirve cualquiera, ya que ha de ser "rica; eso es indispensable" (174). El conde no disimula lo que busca, una esposa que aumente 
su riqueza, lo cual además ayudaría a no mermar la que ya ha acumulado. Se acaba fijando en Clotilde Armández, una chica muy rica, quien además "era de una de las familias más antiguas y bien relacionadas de la La Habana” (202). Clotilde pertenece a lo mejor que tiene que ofrecer Cuba, a la élite criolla de más abolengo. Como buena perteneciente a su género y clase, ella misma piensa que debe casarse y además le da igual con quien sea (223), pero su madre Dña. Luisa sí piensa en el conde, ya que "unía, a sus intachables prendas de carácter, una gran fortuna y un título respetable" (223). Por ambos lados se buscan objetivos similares: los peninsulares buscan aumentar sus fortunas, en este caso a través de un matrimonio ventajoso, y los criollos de fortuna buscan unir sus nombres al de la aristocracia peninsular, con el prestigio consiguiente. Ambas actitudes aparecen caricaturizadas en la novela, y por tanto criticadas, como elementos perniciosos para la sociedad cubana, que a través de esas prácticas entraba en un círculo vicioso en el que siempre se beneficiaban los mismos. En ese sentido, Ania Loomba explica que los romances entre hombres blancos y mujeres de color mostraban un ideal cultural, pero también una metáfora sobre el comercio colonial (158), así la unión entre el hombre español y la mujer criolla cubana muestra una relación de aprovechamiento; no se trata del beneficio de Cuba, sino del de ellos mismos a través de la combinación de los recursos de ambos, lo cual al final resulta en detrimento de la isla.

Aún teniéndolo todo, el conde Coveo sufre de un fenómeno que lo tiene intranquilo: se trata de la presencia de un mendigo que aparece en diferentes partes de la novela y en diferentes lugares que visita el conde, y que ya había aparecido en el teatro donde homenajean al conde al principio de la segunda parte del texto. El mismo mendigo vuelve a aparecer en la puerta de la iglesia en la boda del conde con Clotilde, pero esta vez el conde siente una punzada de culpabilidad, "un remordimiento extraño y repentino de su conciencia" (231). Esto es porque el conde conoce al mendigo, ya que resulta ser el Don Beningno que fue despedido del despacho al principio de la novela para que D. Genaro pudiera continuar con sus corruptelas a sus anchas y cuyo puesto ocupó Vicente Cuevas. Ahora se crea un 
contraste entre ambos: D. Beningno era un buen trabajador, aplicado y honesto, y terminó como mendigo en las calles de La Habana. Mientras, Vicente era un mal trabajador, corrupto, ignorante, y sin embargo termina en lo más alto de la sociedad cubana. Esto pone de manifiesto la crítica hacia esta dinámica: los que progresan y avanzan son los corruptos, los que roban y esquilman los recursos de la nación isleña; mientras que los honestos no llegan a nada, los que podían hacer mejor uso de esos mismos recursos para el mejoramiento de Cuba, terminan como pordioseros en las calles. De esta manera se plasma una alegoría que especifica el pensamiento de los intelectuales cubanos del momento: la metrópoli está terminando con Cuba en su propio beneficio, y por eso es necesaria la independencia.

Estos dos últimos personajes analizados: Clotilde y el mendigo, cristalizan en las escenas finales de la novela para producir una metáfora final sobre cómo Meza veía la situación cubana. El conde y su esposa van a regresar a España, ahora que son ricos, y por tanto, empiezan el proceso de mudanza:

Domingo y González no estaban aquel día en las oficinas; estaban en casa del señor conde: el primero, en mangas de camisa, trepando en una escalera portátil, iba descolgando los cuadros, los espejos, los cortinajes; y González, armado de un martillo y clavos, iba envasando, con puñados de paja y papeles cortados los objetos de cristal, de loza, las estatuas, los jarrones de porcelana. La casa quedaba poco a poco con las paredes desnudas. (262)

Este párrafo entronca con las palabras de Boehmer al decir que "for many peoples imperialsm represented, if not the destruction of their communities and populations, then a harsh existence of dispossession and privation" (20). Con lo cual, la acción de la mudanza es reminiscente de lo que Meza y otros consideraban que se estaba haciendo con la nación cubana: los peninsulares se lo llevaban todo, desmantelaban la isla en beneficio propio y no dejaban nada para los cubanos que eran los que habían hecho el trabajo. Es curiosa la escena en la que se cargan en el 
barco las maletas del conde, que cuando "fueron depositadas en el fondo del bote produjeron cierto sonidillo agudo" (271). Esta imagen recuerda las palabras de Francisco Moreno, quien afirmaba que "la mayoría de los que se encaminan hacia la grande Antilla [...] van dispuestos a no regresar con el mundo [...] vacío" (13). Ambos autores utilizan la misma alegoría para sacar a relucir cómo los españoles en Cuba estaban acabando con los recursos de la isla para su propio enriquecimiento.

Y así se llega al final de la novela, en la que vuelve a aparecer el mendigo que con anterioridad se ha presentado en diferentes momentos de la vida de Vicente. Como queda dicho, este mendigo resulta ser D. Benigno, el empleado que fue despedido al principio de la novela para hacerle sitio a Vicente y a su sobrino, y que ahora yace cadáver (279), mientras Vicente se escapa de Cuba con las riquezas que ha amasado gracias a las corruptelas. Meza propone este contraste como puntilla a la crítica que se ha ido realizando durante toda la novela, máxime cuando el último párrafo de la misma dice que "continuaba libre y abierta la entrada del puerto para tanto bribón que cruzaba por ella" (279), haciendo así franca la desgarrada crítica a la situación de desamparo en que se encontraba la isla con respecto a los españoles que se enriquecían en ella y no dejaban tras de ellos más que miseria.

Por otro lado, la presencia de D. Benigno es sintomática de algo más grande: la ausencia en la novela de los oprimidos por la colonia. Ania Loomba explica que la autoridad colonial debe legitimarse a través de la negociación con la gente que quiere controlar, para lo cual la presencia de esa gente es crucial (51). Además, la misma Loomba explica, siguiendo a Said, que la lengua y la literatura están implicadas en la construcción de una identidad europea y un otro no europeo, lo cual es parte de la creación de la autoridad colonial (73). Sin embargo, en la novela de Meza los colonizadores son los que están presentes, mientras que los colonizados sólo aparecen en la figura de D. Benigno. De esta manera, la crítica se centra en los colonizadores, en la visión esperpéntica que ofrece Meza de la colonialidad cubana y de la presencia corrupta de los españoles. El otro construido en este caso es el 
europeo, que al ser representado como un inútil, ladrón y aprovechado consigue invertir la creación de esa autoridad colonial, desautorizar a España como metrópoli adecuada para los intereses cubanos, y por tanto posibilitar el posicionamiento de Meza a favor de la independencia de la isla.

Así, halagada por personas tan influyentes como José Martí o Reinaldo Arenas, Mi tío el empleado alcanza cotas de texto revolucionario. A través de la presentación de unos personajes esperpénticos, parodiados hasta la saciedad, corruptos y ladrones, representantes de una metrópoli que no era vista como amiga, sino como obstáculo al avance de Cuba y sus ciudadanos, Meza pone de manifiesto sus propias ideas independentistas, hacia las que evolucionó desde el autonomismo. En diálogo con otros pensadores de su época, Meza retrata una sociedad en la que los cubanos no tenían lugar en su propio país y los peninsulares ocupaban todos los puestos de la administración, desde la que robaban a manos llenas sin pudor. Tan mínimo es el lugar de los cubanos en Cuba, que apenas aparecen en la novela de Meza. Ania Loomba dice que el silencio del subalterno no es necesariamente un absoluto (237). De esa manera, la ausencia en el texto de los miembros de la sociedad cubana no hace sino enfatizar la ausencia de los mismos en su propio gobierno, y por ende la necesidad de acabar con una situación colonial que sólo afectaba negativamente a la isla. Anibal Quijano señala que al mirarse en el espejo de la experiencia histórica eurocéntrica, la imagen de América debe resultar necesariamente distorsionada (225-26); esta tendencia se invierte con la novela de Meza: ofrece una visión deforme de los dominantes como forma de exigir que termine su dominio y que Cuba pueda formar su propia imagen, clara y sin distorsiones. 


\section{Bibliografía}

Arenas, Reinaldo. "Meza, el precursor." Revista Iberoamericana, vol. LVI, no. 152-153, jul-dic 1990, doi: http://dx.doi.org/10.5195/reviberoamer.1990.4785.

Bermúdez, Silvia. "La Habana para un exiliado gallego: Manuel Curros Enríquez, La tierra gallega y la modernidad nacional transatlántica." $M L N$, vol. 117, no. 2, Mar. 2002, pp. 331-342.

Bhabha, Homi. "Signs Taken for Wanders: Questions of Ambivalence and Authority under a Tree outside Delhi, May 1817." Critical Inquiry, vol. 12, no. 1, Autumn 1985, pp. 144-165.

Boehmer, Elleke. Colonial and Postcolonial Literature. Migrant Metaphors. 2nd ed. Oxford UP, 2005.

Bravo, Juan Alfonso. "Azúcar y clases sociales en Cuba (1511-1959).” Revista Mexicana de Sociología, vol. 43, no. 3, Jul-Sep 1981, pp. 1189-1228.

Cabrera, Raimundo. Cuba y sus jueces. Imprenta "El Retiro," 1887.

De la Torre, Mildred. Conflictos y cultura política en Cuba. 1878-1898. Editora Política, 2007.

González Freixas, Manuel. "Sociedad y tipos en las novelas de Ramón Meza y Suárez Inclán.” Diss. U of Florida, 1980.

Hernández, Jacinto. Cuba por dentro. n.p. 1871.

Loomba, Ania. Colonialism/Postcolonialism. Routledge, 2002.

Martí, José. "Mi tío el empleado, novela de Ramón Meza." El Avisador Cubano, 25 de abril, 1888.

Meza, Ramón. Mi tío el empleado. Linkgua, 2007. . "Nuestra inmigración útil debe ser protegida." Memoria oficial: Quinta conferencia nacional de beneficencia y corrección de la isla de Cuba. Imprenta "La Moderna Poesía," 1906, pp. 305-334.

Moreno, Francisco. El país del chocolate. (La inmoralidad en Cuba). Imprenta de F. García Herrero, 1887.

Quijano, Aníbal. "Colonialidad del poder, eurocentrismo y América Latina." La colonialidad del saber: eurocentrismo y ciencias sociales. Perspectivas latinoamericanas, recopilado por Edgardo Lander. CLACSO, Consejo Latinoamericano de Ciencias Sociales, 2000, pp. 201-246.

Quiroz, Alfonso. "Corrupción, burocracia colonial y veteranos separatistas en Cuba, 1858-1910." Revista de Indias, vol. XVI, no. 221, 2001, pp. 91-111.

Ramos Martínez, Jon Ander. "Los inmigrantes en Cuba, de región a nación (1880-1902)." 200 años de Iberoamérica (1810-2010). Congreso Internacional: Actas del XIV Encuentro de Latinoamericanistas Españoles, editado por Patricia Calvo González y Eduardo Rey Tristán. Universidade de Santiago de Compostela, 2010, pp. 1041-1050.

Rodríguez Coronel, Rogelio. "Mi tío el empleado: una transgresión modernizadora." Contexto, vol. 11, no. 13, 2007, pp. 151-162. 
Roldán de Montaud, Inés. "La banca española en Cuba (1856-1921)." www.rci.rutgers.edu/\%7Etriner/Session102/Roldan.pdf.

Sánchez, Julio. "Mi tío el empleado de Ramón Meza, novela realista." Romantisme, Réalisme, Naturalisme en Espagne et en Amérique Latine. Publications de L'Université de Lille, 1975, pp. 169-175.

Valle-Inclán, Ramón del. Luces de Bohemia. Espasa-Calpe, 1973.

Villaverde, Cirilo. Cecilia Valdés. Cátedra, 2000. 